\title{
SIMULASI SISTEM INTERLOCK PENGAMAN OPERASI MESIN BERKAS ELEKTRON (MBE) DENGAN PERANGKAT LUNAK BASCOM 8051
}

\author{
SUKARMAN, MUHTADAN \\ Sekolah Tinggi Teknologi Nuklir-BATAN \\ Jl. Babarsari Kotak Pos 6101 YKBB Yogyakarta 55281 \\ Telepon 0274-484085, 489716, Faksimili 0274-489715
}

\begin{abstract}
Abstrak
SIMULASI SISTEM INTERLOCK PENGAMAN OPERASI MESIN BERKAS ELEKTRON (MBE) DENGAN PERANGKAT LUNAK BASCOM 8051. Telah dibuat simulasi sistem pengaman operasi Mesin Berkas Elektron (MBE) berbasis mikrokontroler. Sistem interlock disimulasikan menggunakan perangkat lunak BASCOM 8051. Sebagai masukan ke mikrokontroler diatur dengan memberikan level sinyal $(1 / 0)$ ke port yang terhubung dengan parameter masukan MBE pada editor BASCOM8051. Sebagai keluaran dari Sistem Interlock disimulasikan menggunakan Led Indikator. Hasil pengujian menunjukkan bahwa sistem interlock telah berfungsi sesuai dengan prinsip-prinsip interlock.
\end{abstract}

Kata kunci : mikrokontroler, interlock.

\begin{abstract}
THE SIMULATION OF INTERLOCK FOR ELECTRON BEAM MACHINE (EBM) SAFETY SYSTEM USE BASCOM 8051. The Electron beam machine safety system based BASCOM 8051 has been made. The input regulated to the microcontroller used it. This procedure is called interlock system. the output parameters of the EBM hardware is simulated using 0 or 5 volt option level dipswitch digital signal. The output of interlock system use indicator Led display. The result of this experiment shows that the interlock system has been appropriate to the interlock principles.
\end{abstract}

Keywords : microcontroller, interlock.

\section{PENDAHULUAN}

Mesin Berkas Elektron (MBE) adalah suatu peralatan listrik dan elektronik yang mempercepat elektron hasil pemanasan sebuah filamen, dengan medan listrik dari beda potensial atau tegangan yang relatif tinggi sehingga diperoleh elektron berenergi. Elektron tersebut kemudian digunakan untuk meradiasi sampel percobaan. Dengan demikian MBE dapat juga dikatakan sebagai sumber radiasi yang dioperasikan pada tegangan tinggi. ${ }^{[1]}$

Sebagai sumber radiasi MBE harus mendapat perlakuan yang sama seperti halnya fasilitas iradiasi lainnya terutama pada aspek keselamatan. Aspek keselamatan meliputi aspek keselamatan terhadap manusia, mesin, dan sampel. ${ }^{[2]}$ 
Keselamatan orang meliputi keselamatan operator, pengguna atau publik di sekitar instalasi terhadap bahaya radiasi yang timbul dari interaksi antar elektron. Keselamatan mesin berhubungan dengan tegangan operasi MBE yang relatif tinggi dan harga komponen yang mahal, sedangkan keselamatan sampel berhubungan dengan sampel yang harganya mahal. ${ }^{[3]}$

Mengingat aspek keselamatan di atas, maka operator dalam mengoperasikan MBE harus sesuai dengan prosedur karena parameter-parameter sudah sedemikian rupa diinterlock. Oleh karena itu dibuatlah simulasi sistem interlock untuk monitoring sehingga aspek keamanan tetap terjamin.

\section{TINJAUAN UMUM INTERLOCK MESIN BERKAS ELEKTRON (MBE)}

Prinsip kerja Mesin Berkas Elektron secara singkat dapat dijelaskan sebagai berikut: elektron dihasilkan oleh sumber elektron yang umumnya berupa filamen yang dipanaskan dengan arus listrik sehingga menghasilkan elektron-elektron bebas. Elektron-elektron tersebut didorong dengan katoda pendorong yang mempunyai potensial negatif dan selanjutnya ditarik dengan anoda yang mempunyai potensial positif. Selanjutnya, elektron-elektron dipercepat lagi dengan sumber tegangan tinggi. Elektron yang telah dipercepat difokuskan dan diarahkan dengan sistem pemfokus serta pengarah berkas. Akhirnya berkas elektron dipayarkan dengan sistem pemayar berkas untuk mengirradiasi bahan atau target. Secara sederhana skema Mesin Berkas Elektron dapat dilihat pada Gambar 1.

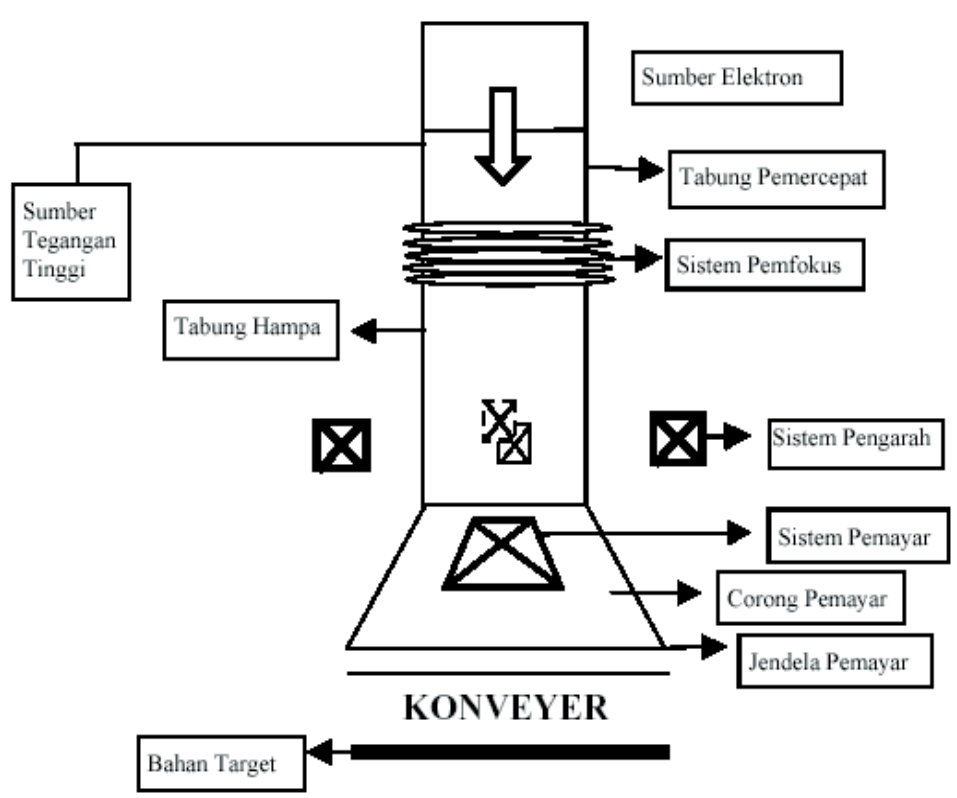

Gambar 1. Skema Mesin Berkas Elektron 
umumnya sebuah Mesin Berkas Elektron (MBE) terdiri dari beberapa komponen utama yaitu sumber tegangan tinggi, sumber elektron, tabung akselerator, sistem optik berkas elektron, sistem hampa dan sistem konveyor. Sistem optik terdiri dari sistem pemayar, sistem pemfokus, dan sistem pengarah.

\section{Prinsip Interlock Mesin Berkas Elektron}

Interlock MBE adalah sebuah sistem untuk menjaga aspek-aspek keselamatan, di antaranya yaitu keselamatan untuk orang, mesin, dan sampel (terutama sampel yang harganya mahal).

Untuk mendapatkan keandalan bagi sistem keselamatan suatu instalasi MBE maka perlu diterapkan bagian dari filosofi keselamatan pada instalasi tersebut yang disebut metoda redudansi yaitu penggunaan lebih dari jumlah minimum parameterparameter yang diperlukan untuk mendapatkan fungsi keselamatan yang lebih baik. ${ }^{[4]}$ Kerja parameter-parameter tersebut dapat dikoordinasikan dalam suatu sistem yang disebut sistem interlock. Parameter-parameter keselamatan dalam sistem interlock biasanya berupa parameter yang dapat dilihat (visible: misalnya lampu), parameter yang dapat didengar (audible: misalnya bel alarm), parameter fisika, dan parameter listrik.

\section{Parameter-Parameter Interlock Mesin Berkas Elektron}

Di dalam instalasi MBE PTAPB dipasang empat belas (14) parameter interlock yang berfungsi menjaga aspek keselamatan orang, mesin dan sampel.

Keselamatan orang meliputi keselamatan operator, peneliti, atau publik yang berada di dalam atau disekitar instalasi terhadap bahaya radiasi yang timbul dari interaksi antara elektron itu sendiri. Keselamatan mesin perlu diperhatikan karena MBE beroperasi pada tegangan yang relatif tinggi dan mempunyai komponenkomponen yang mahal. Keselamatan sampel terutama sampel yang harganya mahal perlu diperhatikan, terhadap dosis radiasi yang berlebihan karena kegagalan sistem transportasinya (konveyor).

Empat belas (14) masukan parameter interlock itu adalah: vakum, monitor orang, emergency-1, emergency-2, suhu ruang, kunci kontak operasi, pemayar, konveyor, berkas bocor, blower window, pemfokus, HV, dan door lock darurat. Hubungan parameter masukan interlock MBE dan keluarannya ditampilkan pada Tabel 1, yang telah dikelompokkan. 
Tabel 1. Hubungan Masukan dan Keluaran dari Parameter Interlock Yang Dikelompokkan

\begin{tabular}{|c|c|c|c|c|}
\hline No & Nama Port & Keterangan & Parameter & Kelompok \\
\hline 1 & P1.0 & Input & Emergency-1 & \multirow{3}{*}{$\begin{array}{l}\text { Interlock Door } \\
\text { Lock }\end{array}$} \\
\hline 2 & P1.1 & Input & Emergency-2 & \\
\hline 3 & P1.2 & Input & Darurat & \\
\hline 4 & P1.3 & Input & Vakum & \multirow{5}{*}{$\begin{array}{l}\text { Interlock } \\
\text { mengeset HV }\end{array}$} \\
\hline 5 & P1.4 & Input & Monitor Orang & \\
\hline 6 & P1.5 & Input & Suhu ruang & \\
\hline 7 & P1.6 & Input & Door lock & \\
\hline 8 & P1.7 & Input & Kunci kontak operasi & \\
\hline 9 & P3.0 & Input & HV & \multirow{6}{*}{$\begin{array}{l}\text { Interlock } \\
\text { mengeset SE }\end{array}$} \\
\hline 10 & P3.1 & Input & Pemayar & \\
\hline 11 & P3.2 & Input & Pemfokus & \\
\hline 12 & P3.3 & Input & Berkas bocor & \\
\hline 13 & P3.4 & Input & Blower window & \\
\hline 14 & P3.5 & Input & Konveyor & \\
\hline 15 & P2.0 & Output & Darurat & \multirow{7}{*}{$\begin{array}{l}\text { Indikator } \\
\text { Keluaran }\end{array}$} \\
\hline 16 & P2.1 & Output & Door lock & \\
\hline 17 & P2.2 & Output & HV siap & \\
\hline 18 & P2.3 & Output & Warning lamp & \\
\hline 19 & P2.4 & Output & Bell alarm & \\
\hline 20 & $\mathrm{P} 2.5$ & Output & Blower & \\
\hline 21 & P2.6 & Output & SE siap diset & \\
\hline
\end{tabular}

Keterangan :

Interlock door lock : pintu ruang MBE akan terbuka/aktif jika kelompok masukan terpenuhi. Interlock Mengeset HV: tegangan tinggi HV dapat diset jika kelompok masukan terpenuhi. Interlock SE $\quad$ : sumber elektron dapat di set jika kelompok masukan terpenuhi Indikator keluaran $\quad$ : lampu indikator berupa LED yang akan menyala jika syarat interlock masing-masing kelompok terpenuhi.

Pada Gambar 2. nampak hubungan masukan dan keluaran dari parameter interlock secara skematik. Paramater Power ac, monitor ozon dan monitor radiasi tidak termasuk dalam parameter interlock. 


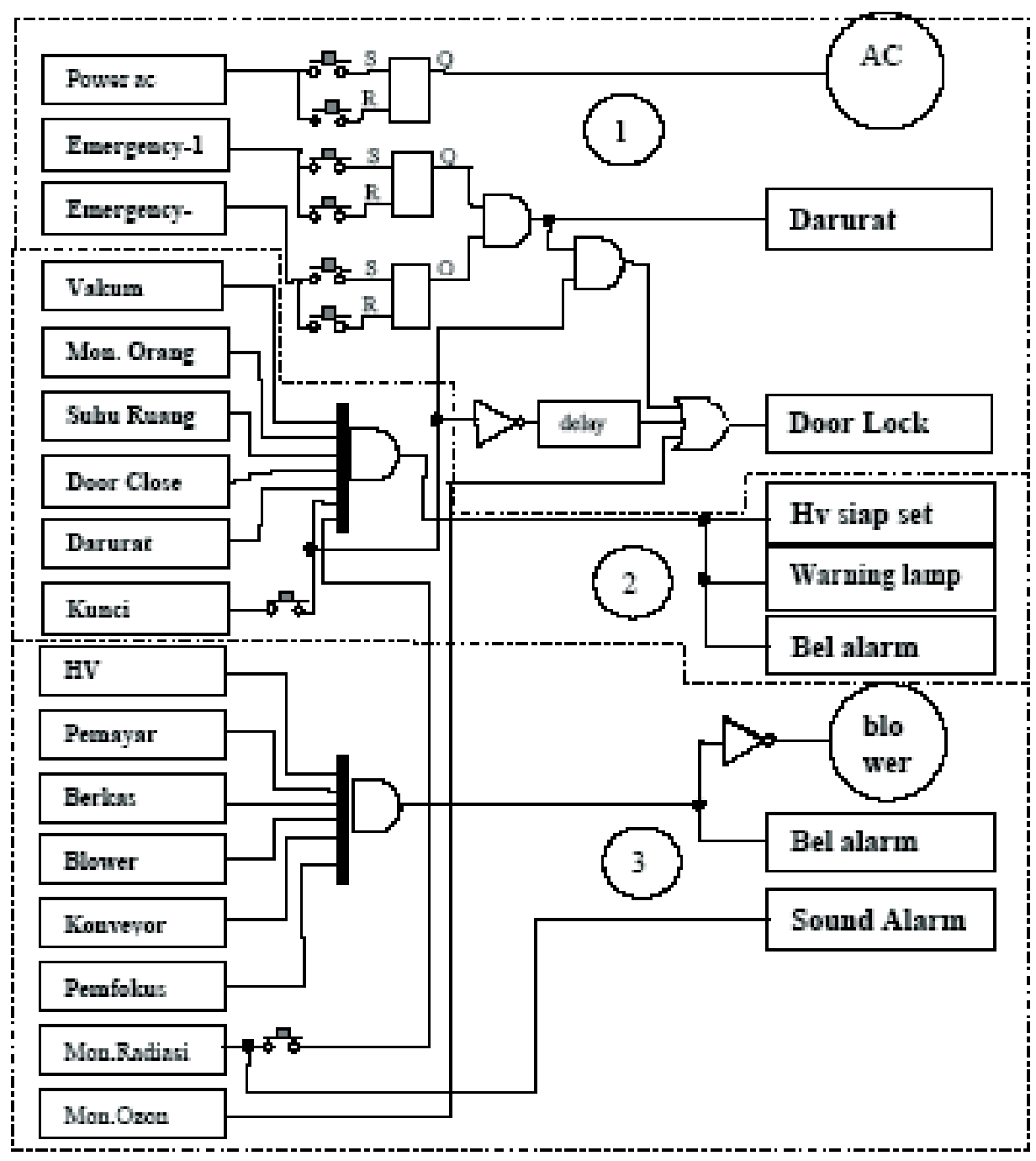

Gambar 2. Blok Diagram Sistem Interlock MBE

Pada Gambar 3 ditunjukkan diagram alir sistem interlock MBE. 


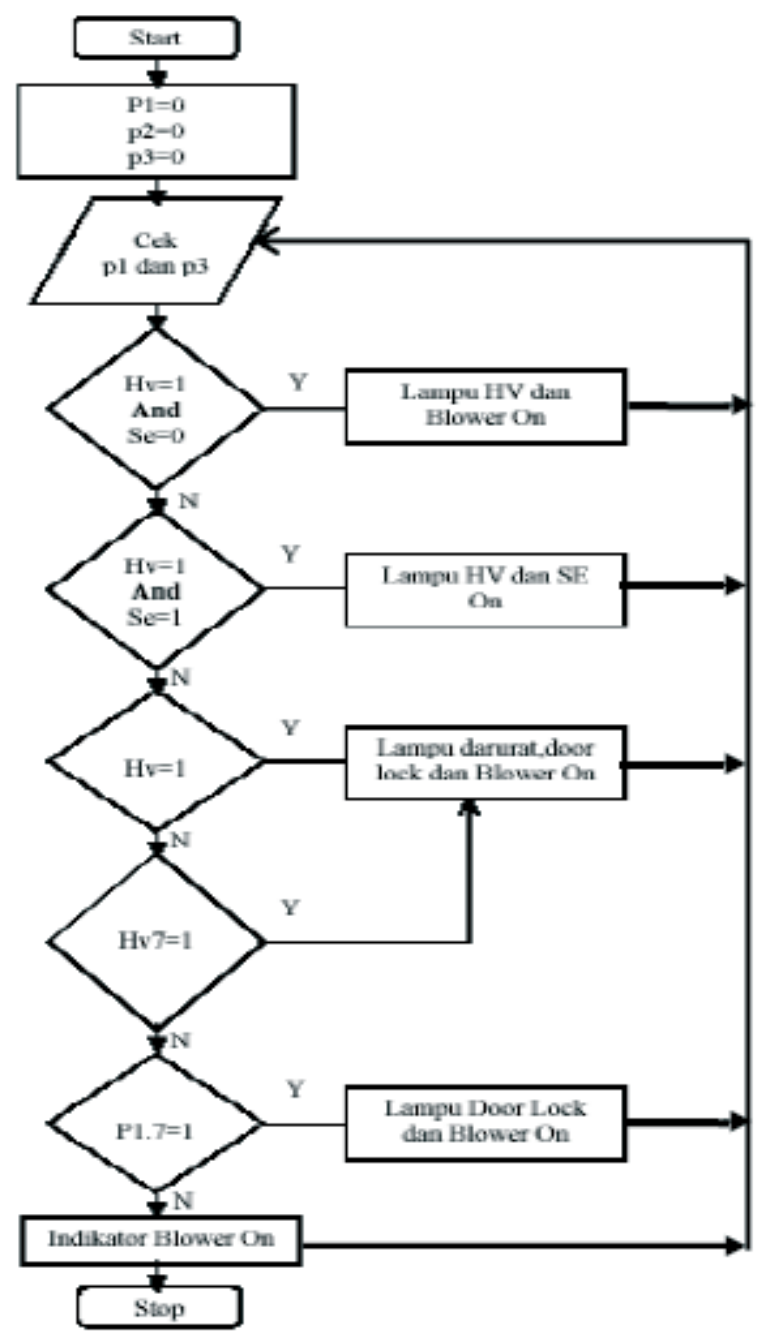

Gambar 3. Diagram Alir Sistem Interlock MBE dengan perangkat lunak bascom 8051

\section{METODE PENGERJAAN}

\section{Alat dan Bahan}

Alat yang diperlukan meliputi Personal Komputer (PC) dan perangkat Lunak BASCOM 8051.

\section{Pelaksanaan}

1. Perangkat lunak BASCOM 8051 dibuka dan editornya digunakan untuk mengedit.

2. Port masukan dan keluaran ditentukan dari software BASCOM 8051 yang mewakili masukan/keluaran parameter interlock. 
3. Program dikompilasi dan program dijalankan (Running), ubahlah masukan dengan cara menekan port mikrokontroler menggunakan Mouse dan amati keluaran program, tampak pada Gambar 4.

4. Jika program sudah berjalan sesuai dengan keinginan maka program disimpan. Jika hasil eksekusi belum sesuai program diubah lagi.

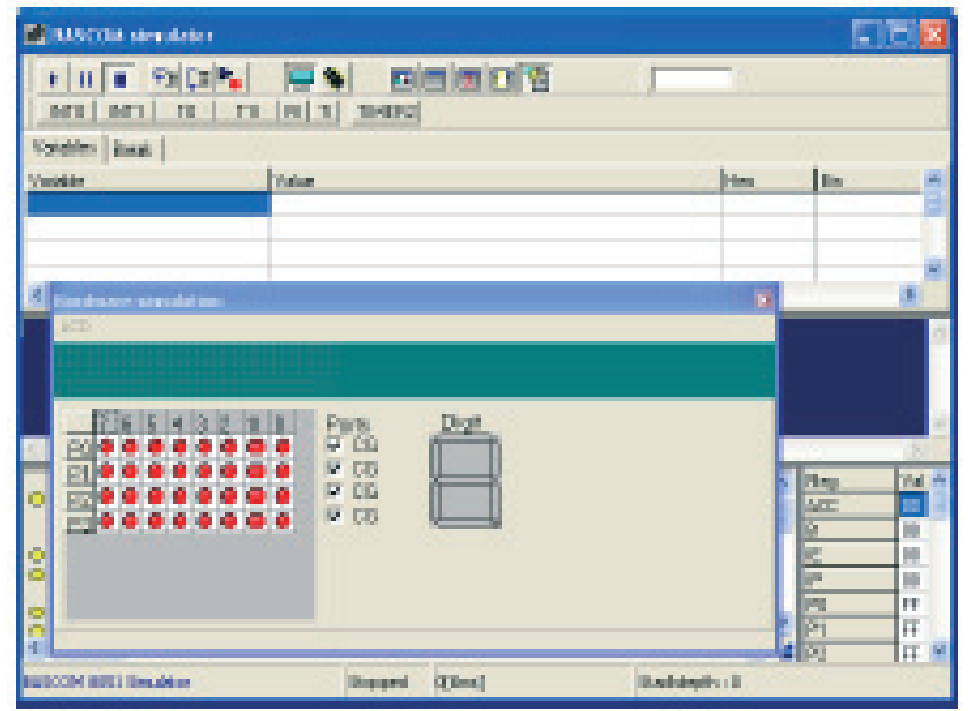

Gambar 4. Simulasi Sistem Interlock MBE Menggunakan Bascom 8051

\section{HASIL DAN PEMBAHASAN}

Pada instalasi Mesin Berkas elektron di PTAPB terdapat tujuh belas (17) parameter interlock yang direncakan namun hanya empatbelas (14) saja yang akan diinterlock. Semua parameter ditujukan untuk menjaga aspek keselamatan orang, mesin dan sampel. Dalam Simulasi sistem pengaman operasi MBE menggunakan perangkat lunak BASCOM 8051

Keluaran dari parameter MBE digunakan sebagai masukan bagi simulator BASCOM 8051, sedangkan pin-pin yang terhubung dengan parameter output dihubungkan dengan LED. Parameter input dan output ini menggunakan logika 0 dan 1. Untuk input logika 0 adalah 0 volt dan logika 1 adalah +5 volt. Pada output logika 0 lampu LED akan padam dan logika 1 lampu LED menyala.

Sebelum pembuatan program aplikasi yang akan diisikan ke dalam IC AT89C51 menggunakan bahasa pemrograman BASCOM (Basic Compiler) 8051 buatan MCS Electronics perlu dilakukan simulasi terlebih dulu. List simulasi program dapat dilihat pada Gambar 5.

Hasil kompilasi dan simulasi program pada sistem interlock ini nampak pada Gambar 6. variabel Hv1 adalah hasil Logika dari $\mathrm{p} 1.0$ and $\mathrm{p} 1.1$. Jika port $\mathrm{p} 1.0=1$ dan Led p1.0 menyala dan p1.1 $=1$ dan led p1.1 menyala maka hasil logika AND kedua 
port menghasilkan nilai 1 yang disimpan pada variabel Hv1 yang berharga Hv1=1, demikian seterusnya tahapan pengujian dapat dimonitor sampai program dianggap sesuai.

Dim $\mathrm{Hv}$ as bit

Dim hv1 as bit

Dim hv2 as bit

Dim hv3 as bit

Dim hv4 as bit

Dim hv5 as bit

Dim hv6 as bit

Dim hv7 as bit

Dim se as bit

Dim sel as bit

Dim se2 as bit

Dim se 3 as bit

Dim se 4 as bit

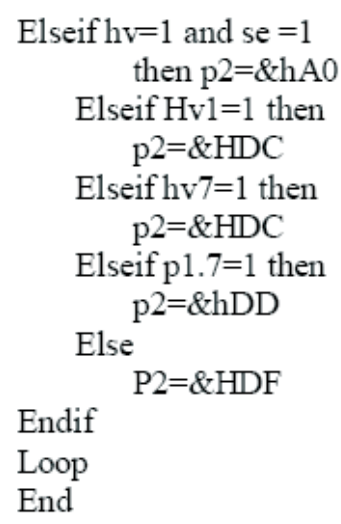

$\mathrm{P} 0=\& \mathrm{~h} 00$

$\mathrm{P} 1=\& \mathrm{~h} 00$

$\mathrm{P} 2=\& \mathrm{~h} 00$

$\mathrm{P} 3=\& \mathrm{~h} 00$

Do

$\mathrm{Hv} 1=\mathrm{p} 1.0$ and $\mathrm{p} 1.1$

$\mathrm{Hv} 2=\mathrm{p} 1.2$ and $\mathrm{p} 1.3$

$\mathrm{Hv} 3=\mathrm{p} 1.4$ and $\mathrm{p} 1.5$

$\mathrm{Hv} 4=\mathrm{p} 1.6$ and $\mathrm{p} 1.7$

Hv5 $=$ hv1 and hv2

Hv6 $=h v 3$ and hv 4

$\mathrm{Hv} 7=\mathrm{hv} 1$ and $\mathrm{p} 1.7$

$\mathrm{Hv}=\mathrm{hv} 5$ and hv6

Se1 $=$ p3. 0 and p3.1

$\mathrm{Se} 2=\mathrm{p} 3.2$ and $\mathrm{p} 3.3$

$\mathrm{Se} 3=\mathrm{p} 3.4$ and $\mathrm{p} 3.5$

$\mathrm{Se} 4=\mathrm{se} 1$ and se2

$\mathrm{Se}=\mathrm{se} 3$ and se 4

If $\mathrm{hv}=1$ and $\mathrm{se}=0$ then

$\mathrm{P} 2=\& \mathrm{hC} 0$

Gambar 5. List Program Simulasi Sistem Interlock Pengaman MBE dengan Perangkat Lunak BASCOM 8051

Setelah pembuatan program selesai, program disimpan dengan ekstensi .bas. Kemudian program di-compile. Apabila tidak terjadi kesalahan maka akan dihasilkan 
file dalam ekstensi .BIN, .DBG, .HEX, dan .RPT. File dalam format HEX inilah yang nantinya akan diisikan ke dalam chip AT89C51

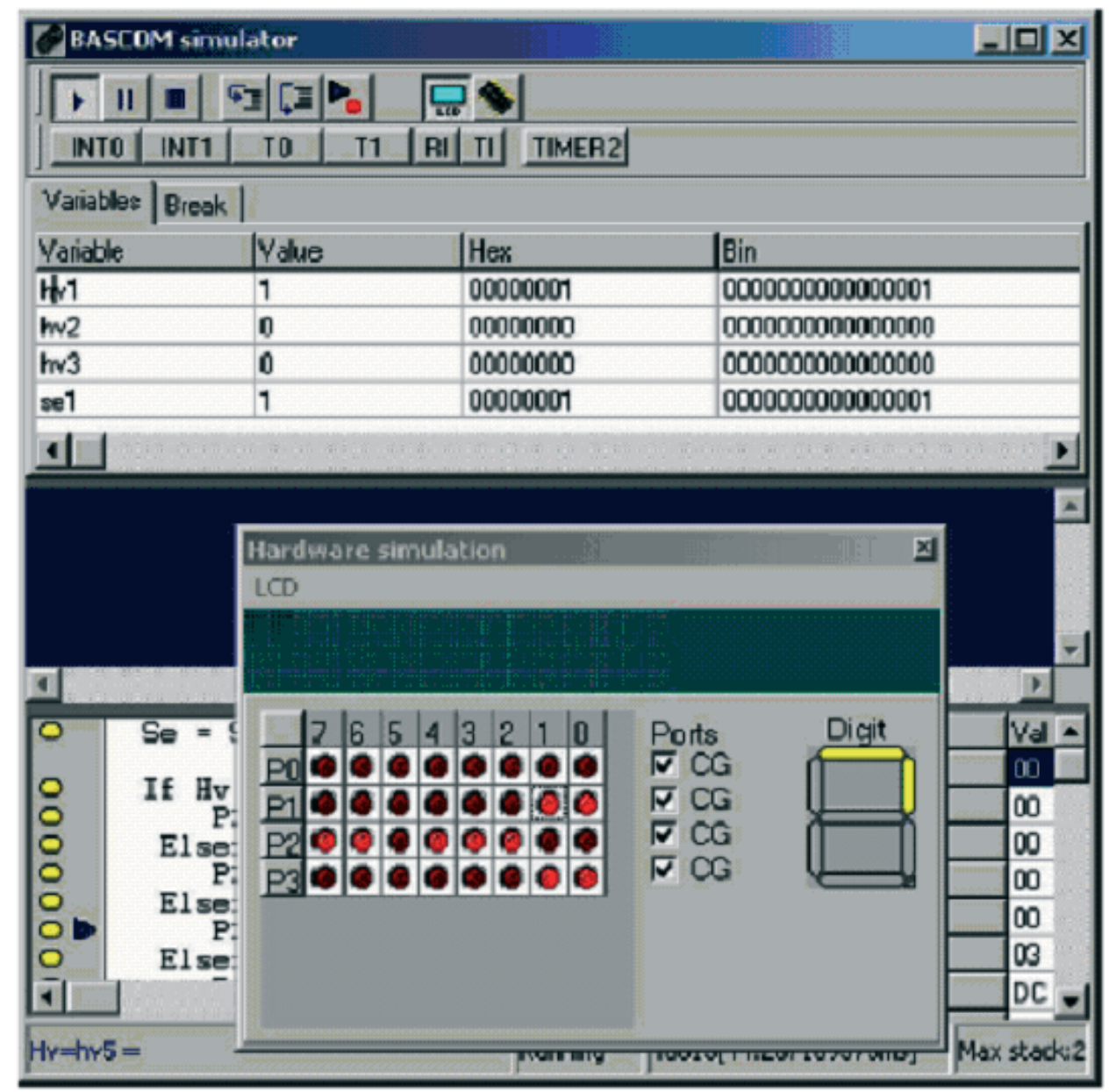

Gambar 6. Hasil Kompilasi dan Simulasi Program Pada Sistem Interlock MBE dengan Perangkat Lunak BASCOM 8051

Pada bagian kelompok keluaran (Darurat,door lock,Hv siap warnign lamp,bell alarm, blower dan SE siap diset) akan menyala pada LED indikator apabila semua parameter Masukan kelompok-1 pada port-1 (p1.0-p1.7) memenuhi syarat interlock atau batas yang ditentukan dan Led Indikator keluaran akan mati (OFF) apabila ada salah satu parameter input kelompok 1 mengalami kegagalan. LED indikator SE siap diset akan menyala apabila semua paramater input kelompok 1 dan 2 memenuhi syarat atau batas yang ditentukan. LED indikator Blower adalah kebalikan dari LED indikator SE siap diset, sehingga akan menyala apabila LED indikator SE siap diset mati dan akan mati apabila LED indikator SE siap diset menyala. 


\section{KESIMPULAN}

Berdasarkan hasil percobaan di atas dapat disimpulkan sebagai berikut :

1. Telah disimulasikan 14 parameter masukan pada sistem interlock MBE dengan perangkat lunak BASCOM 8051.

2. Unjuk kerja dari Sistem interlock atau pengaman operasi MBE dapat diamati sebelum program ini ditanam ke Chip mikrokontroler.

\section{DAFTAR PUSTAKA}

1. PUDJO R. D,, 2004, 'Teknologi Mesin Berkas Elektron”, Diktat Materi Kuliah BATAN Accelerator School, P3TM-BATAN, Yogyakarta.

2. SUDIYANTO dan SUJATMOKO, 1996, "Perancangan Mesin Berkas Elektron 500 Kev/10 mA", Seminar Sehari Perancangan Mesin Berkas Elektron, PPNY-Batan, Yogyakarta.

3. ANONIM, 1996, "Kumpulan Makalah Seminar Sehari Perancangan Mesin Berkas Elektron $500 \mathrm{KeV} / 10 \mathrm{~mA}$ ", PPNY-BATAN, Yogyakarta.

4. MIRANTI, 2005 "Model Simulasi Sistem Interlock MBE P3TM BATAN dengan Labview", Yogyakarta. 